\title{
Method for Estimation of Aerosol Parameters Based on Ground Based Atmospheric Polarization Irradiance Measurements
}

\author{
Kohei Arai 1 \\ Graduate School of Science and Engineering \\ Saga University \\ Saga City, Japan
}

\begin{abstract}
Method for aerosol refractive index estimation with ground based polarization measurement data is proposed. The proposed method uses a dependency of refractive index on $p$ and $s$ polarized down welling solar diffuse irradiance. It is much easy to measure $p$ and $s$ polarized irradiance on the ground with a portable measuring instrument rather than solar direct, diffuse and aureole measurements. Through theoretical and simulation studies, it is found that the proposed method show a good estimation accuracy of refractive index using measured down welling $p$ and $s$ polarized irradiance data with a measuring instrument pointing to the direction which is perpendicular to the sun in the principal plane. Field experimental results also show a validity of the proposed method in comparison to the estimated results from the conventional method with solar direct, diffuse and aureole measurement data.
\end{abstract}

Keywords- Degree of Polarization; aerosol refractive index; size distribution

\section{INTRODUCTION}

The largest uncertainty in estimation of the effects of atmospheric aerosols on climate stems comes from uncertainties in the determination of their microphysical properties, including the aerosol complex index of refraction, which in turn determines their optical properties. The methods that allow estimation of refractive indices have being proposed so far (Shaw, G.E. 1976, Hoppel W.A., et al., 1990, Holben B.N. et al., 1991). Most of the methods use ground based direct, diffuse and aureole measurement data such as AERONET (Holben B.N. et al., 1998) and SKYNET Aoki, K. et al., 2005). The methodology for estimation of a complete set of vertically resolved aerosol size distribution and refractive index data, yielding the vertical distribution of aerosol optical properties required for the determination of aerosol-induced radiative flux changes is proposed (Reddemann, J. et al., 2000). The method based on the optical constants determined from the radiative transfer models of the Jovian atmosphere is also proposed (Clapp M.L. et al., 1996). Laboratory based refractive indices estimation methods with spectral extinction measurements are proposed (Eiden R., 1971, Thomas G.E., et al., 2005). Refractive index and size distribution as well as single scattering albedo, Angstrome exponent, volume spectrum are, in general, estimated with ground based solar direct, diffuse and aureole data together with measured optical depth. Instrument that allows measurement is, in general, comparatively heavy and relatively large in comparison to the sun-photometer and polarized irradiance measuring instruments. They are not portable so that it is difficult to measure solar direct, aureole and diffuse irradiance at anywhere.

Measuring instrument for Degree of Polarization: DP, in turn, is portable and relatively light as well as comparatively small in comparison to the instrument. From optical depth measurement data in several atmospheric transparent wavelength channels, aerosol optical depth, and refractive index and size distribution are estimated. For instance, Junge parameter is estimated from Angstrome exponent derived from the optical depth measurement. DP, meanwhile, depends on molecule scattering (phase function of Rayleigh scattering) which is determined from atmospheric pressure and so on, aerosol scattering (phase function of Mie scattering) which is determined from refractive index and so on. Furthermore, it depends on surface reflectance so that surface reflectance, optical depth of molecule, aerosol and the other atmospheric components have to be known, then it might be possible to estimate DP results in estimation of refractive index and size distribution.

\section{PROPOSED METHOD}

\section{A. Default Parameters}

The proposed method utilizes a scattering angle dependency of DP on aerosol parameters, refractive index (Real: Re and Imaginary: Im) and size distribution. Junge parameter: Jp is chosen for size distribution model of which there are a variety of models, Junge, logarithmic normal, power of low, etc. (only one parameter is enough to represent size distribution). Obviously, scattering angle dependency of DP is highly related to the aerosol parameters so that it is possible to estimate the aerosol parameters with the measured DP of different scattering (observation) angle characteristics. In the principal plane composed with sun and the test site location, $\mathrm{p}$ and s polarized solar diffuse irradiance is measured with several different observation angles. Observation angle dependency of DP which is calculated with the measured $p$ and $\mathrm{s}$ polarized irradiance is then compared to a previously calculated scattering angle dependency of DP with the possible parameters of Re, Im, and Jp which is shown in Table 1. 
TABLE I. POSSIBLE PARAMETERS FOR DP CALCULATIONS (TYPICAL PARAMETER SET IS RE $=1.5$, IM=0.015, JP=3.0)

\begin{tabular}{|c|c|c|c|c|c|c|c|}
\hline $\operatorname{Re}$ & 1.35 & 1.40 & 1.45 & 1.50 & 1.55 & 1.60 & 1.65 \\
\hline $\mathrm{Im}$ & 0.0001 & 0.005 & 0.010 & 0.015 & 0.020 & 0.025 & 0.030 \\
\hline $\mathrm{Jp}$ & 2.4 & 2.6 & 2.8 & 3.0 & 3.2 & 3.4 & 3.6 \\
\hline
\end{tabular}

In this case, step size of Re is 0.05 while that of $\mathrm{Im}$ is 0.005 and that of $\mathrm{Jp}$ is 0.2 . After finding an initial parameter set of a combination of Re', Im', and Jp', More accurate solution estimation is tried to find out a best-fit scattering angle dependency by using golden section method. Thus bestfit scattering dependency of DP in a least square mean is determined results in find out a most appropriate set of parameters, Re, Im, and Jp.

\section{B. Sensitivity Analysis}

In order to determine most appropriate observation angles, a sensitivity analysis is conducted. Let $(\partial \mathrm{DP} / \partial \mathrm{x})$ be sensitivity of $\mathrm{x}$ to DP where $x$ denotes $\mathrm{Re}$, Im and Jp. Sensitivity for all the possible combinations of aforementioned parameters are estimated with the calculated DP derived from MODTRAN Mie code. Estimated sensitivities for Re, Im, and DP are shown in Figure 1.

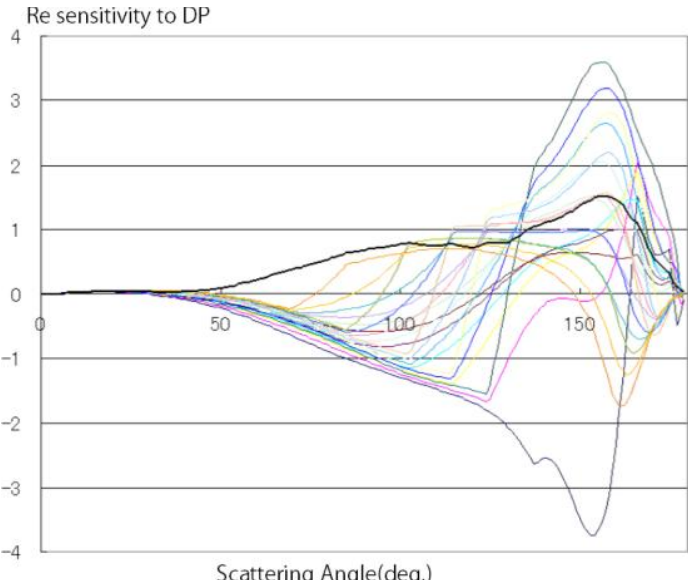

(a) Real part of refractive index

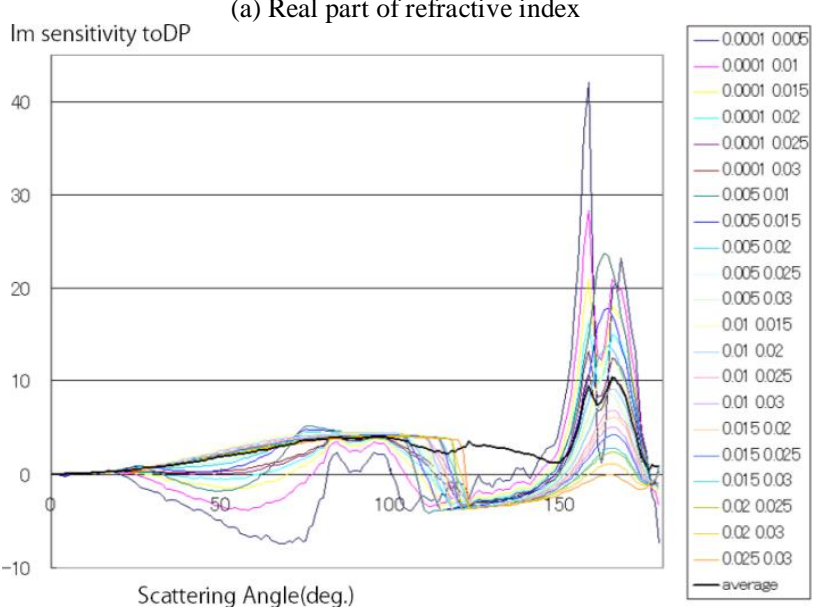

(b) Imaginary part of refractive index

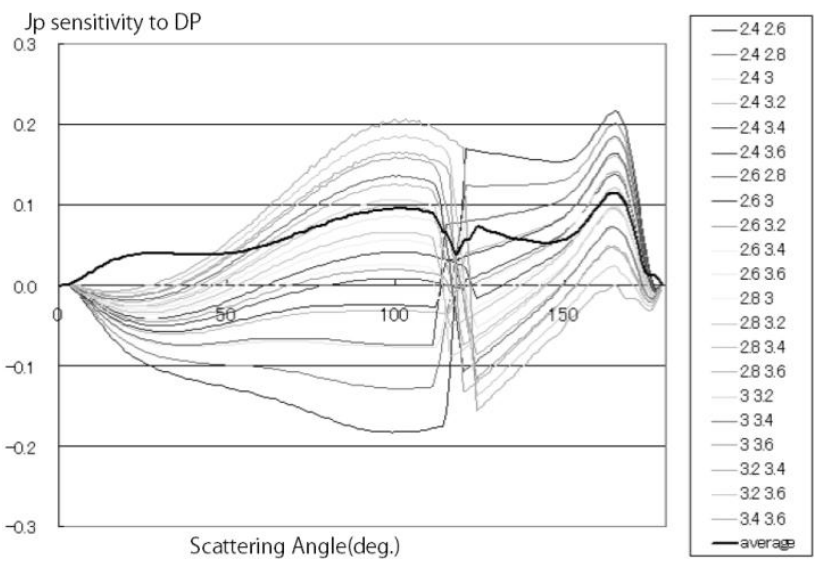

(c) Junge parameter

Fig. 1. Sensitivity Of Refractive Index: Re And Im And Junge Parameter: Jp To Degree Of Polarization: DP

There two peaks in the sensitivity characteristics for Re, Im, and DP at around 90 and 170 degrees of scattering angles. The peak at 90 degree is relatively stable in comparison to that at 170 degree so that 90 degree of observation (scattering) angle (perpendicular to the sun) is more recommendable.

\section{Single Scattering Albedo}

In this calculation, single scattering albedo is also calculated. Figure 2 shows the single scattering albedo with the possible parameters. Obviously, single scattering albedo decreases in accordance with increasing of imaginary part. Also single scattering albedo increases in accordance with increasing of real part of refractive index.

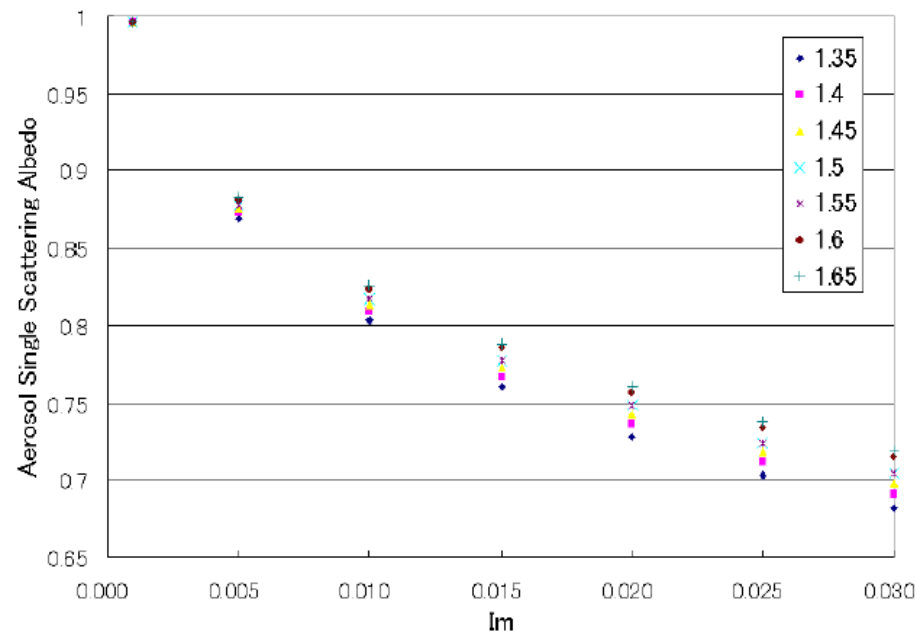

Fig. 2. Single scattering albedo as functions of real and imaginary parts of refractive index

\section{DP Dependency on Aerosol Optical Depth, and Surface Reflectance}

DP decreases in accordance with increasing of aerosol optical depth due to the fact that multiple scattering increases with increasing of aerosol optical depth results in decreasing of DP. Meanwhile, DP decreases in accordance with increasing of surface reflectance due to the almost same reason for aerosol optical depth. Averaged DP sensitivity of 
aerosol optical depth and surface reflectance shows two peaks at 20 and 90 degrees for aerosol optical depth while at 35 and 90 degrees for surface reflectance so that it would be better to measure DP at the second peak at 90degree which is much sensitive to DP rather than 20 and or 35 degrees.

DP as function of aerosol optical depth and surface reflectance as well as DP sensitivity of aerosol optical depth and surface reflectance are shown in Figure 3.

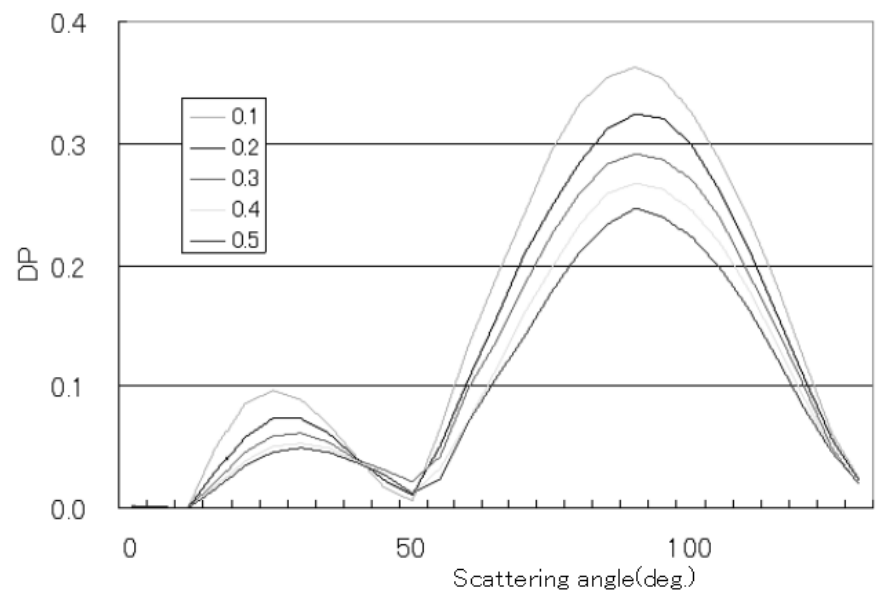

(a) DP as a function of aerosol optical depth

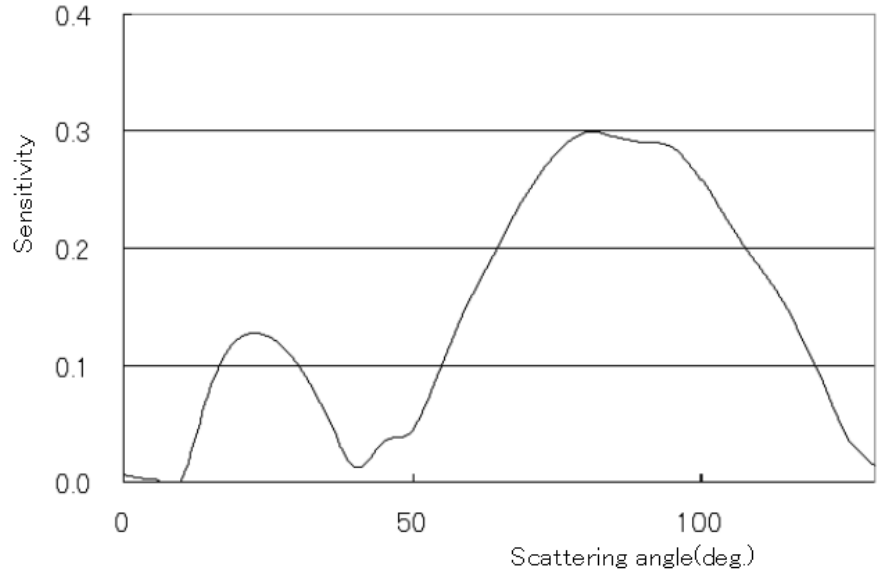

(b) DP sensitivity of aerosol optical depth

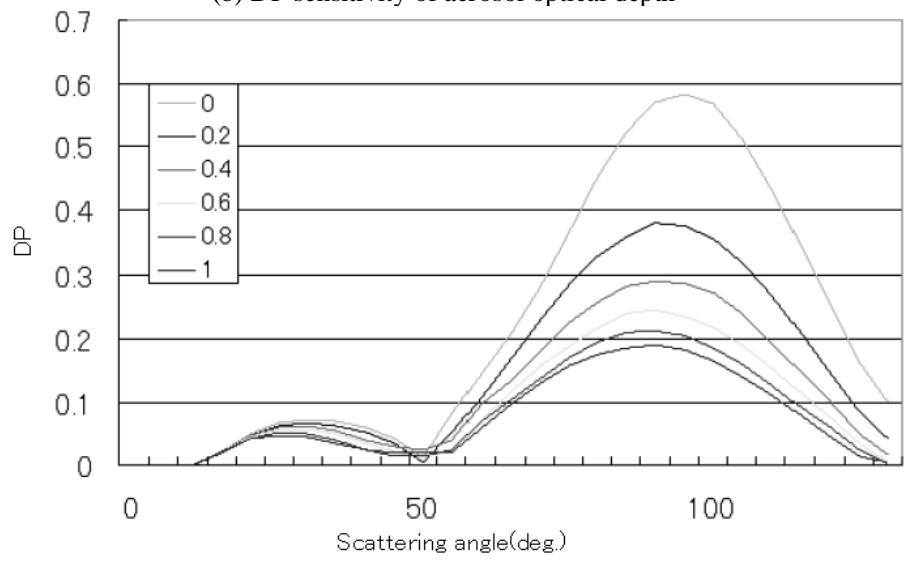

(c) DP as a function of surface reflectance

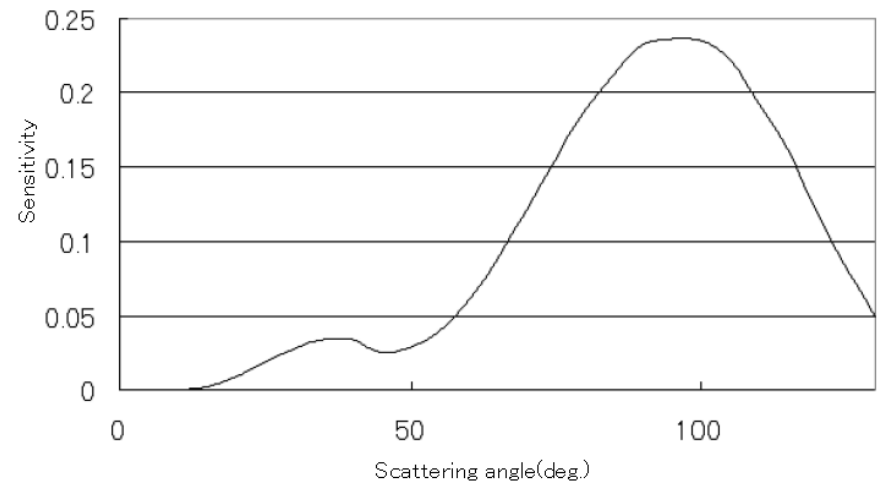

(d) DP sensitivity of surface reflectance

Fig. 3. DP as function of aerosol optical depth and surface reflectance as well as DP sensitivity of aerosol optical depth and surface reflectance.

\section{E. Phase Function, DP and Sensitivity}

Phase function of $\mathrm{p}$ and $\mathrm{s}$ polarized irradiance, DP as functions of aerosol refractive index and Junge parameter, and DP sensitivity of refractive index and Junge parameter are estimated. It is found that the sensitivities of real and imaginary parts of refractive index are greater than that of Junge parameter as is shown in Figure 4. Also it is found that there are two peaks in sensitivity at around 20 and 90 degrees of scattering angle. Therefore, it would be better to measure DP at the scattering angle of 90 degree for refractive index and Junge parameter estimation.

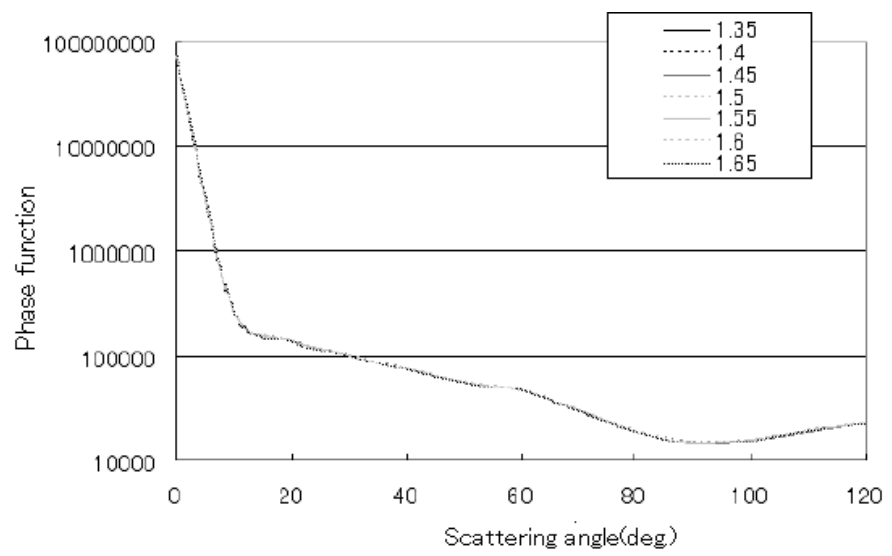

(a) Phase function of p polarized irradiance (real part)

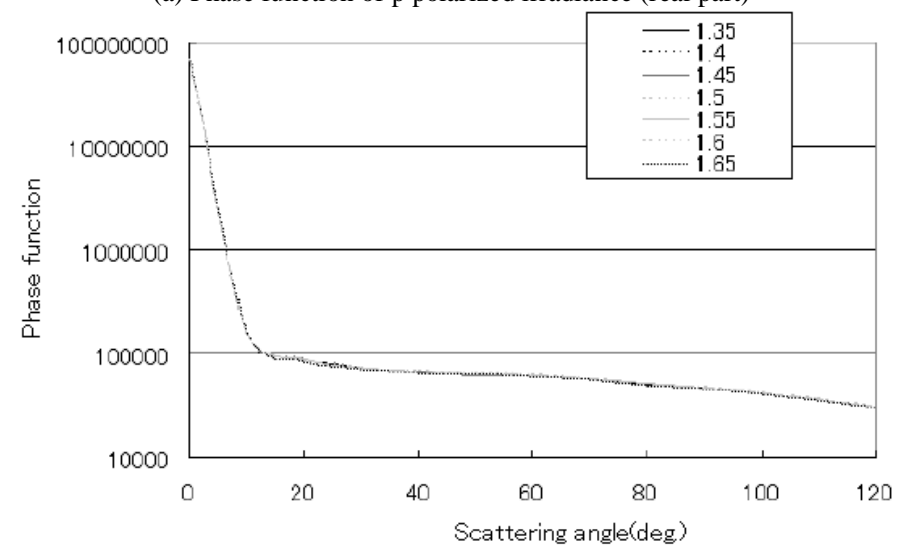

(b) Phase function of s polarized irradiance 


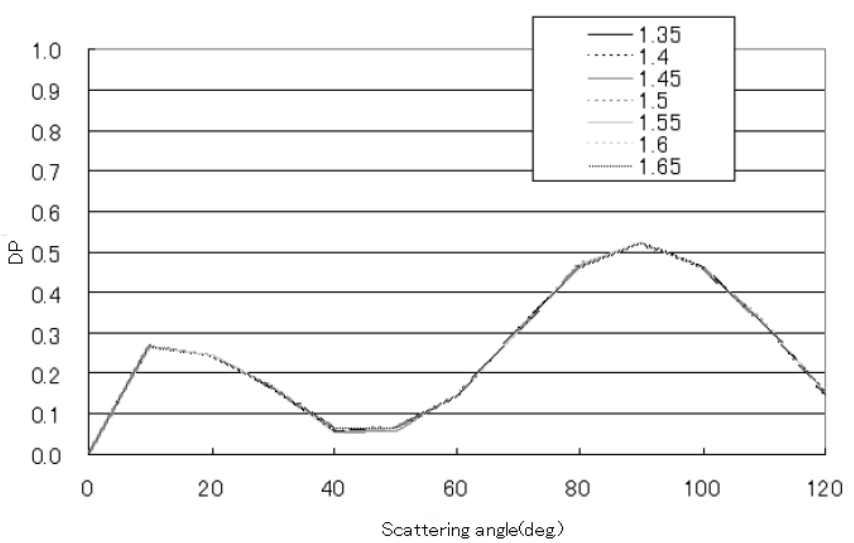

(c) DP as a function of real part of refractive index

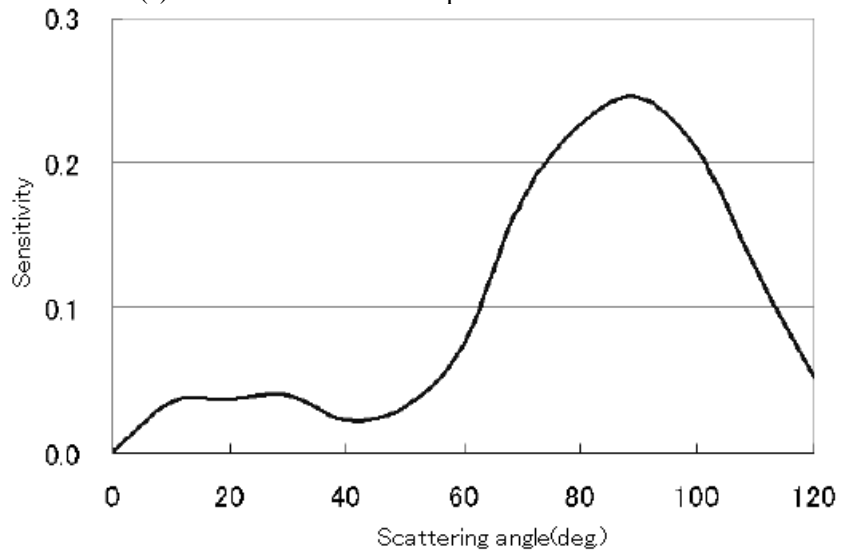

(d) DP sensitivity of real part of refractive index

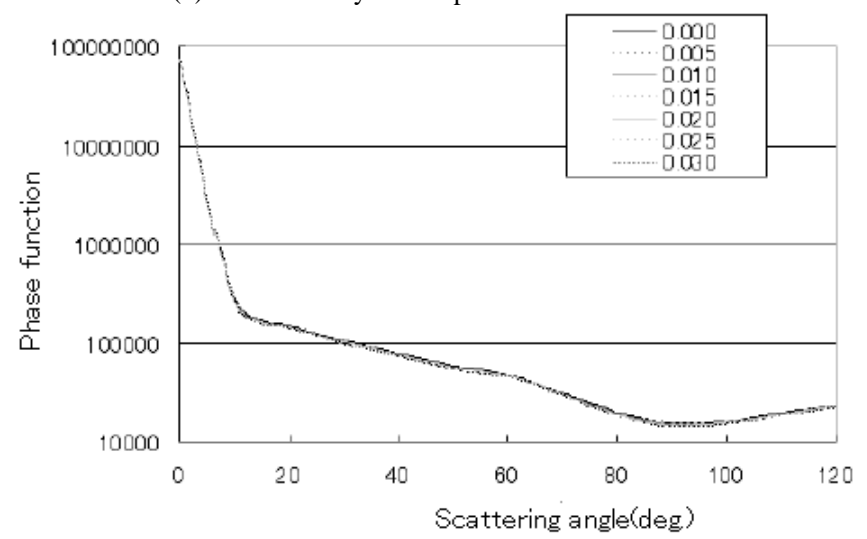

(e) Phase function of p polarized irradiance (imaginary)

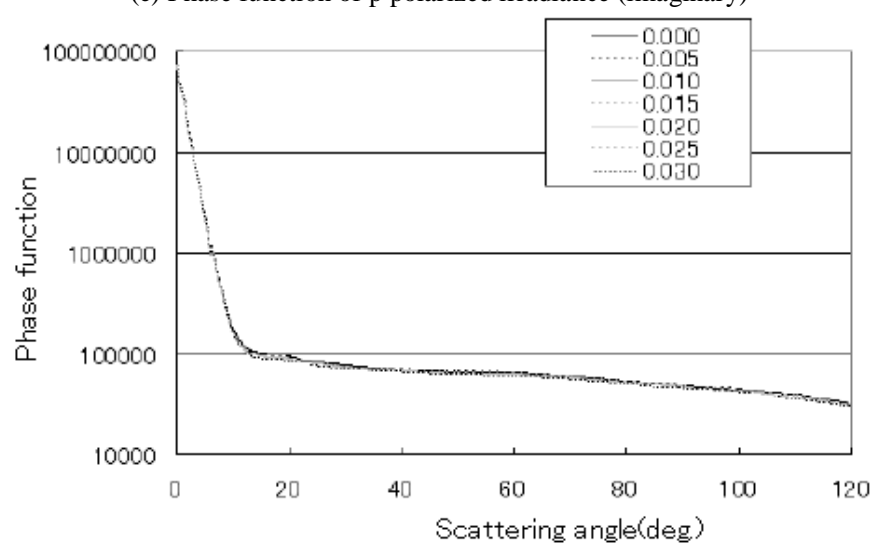

(f) Phase function of s polarized irradiance (imaginary)

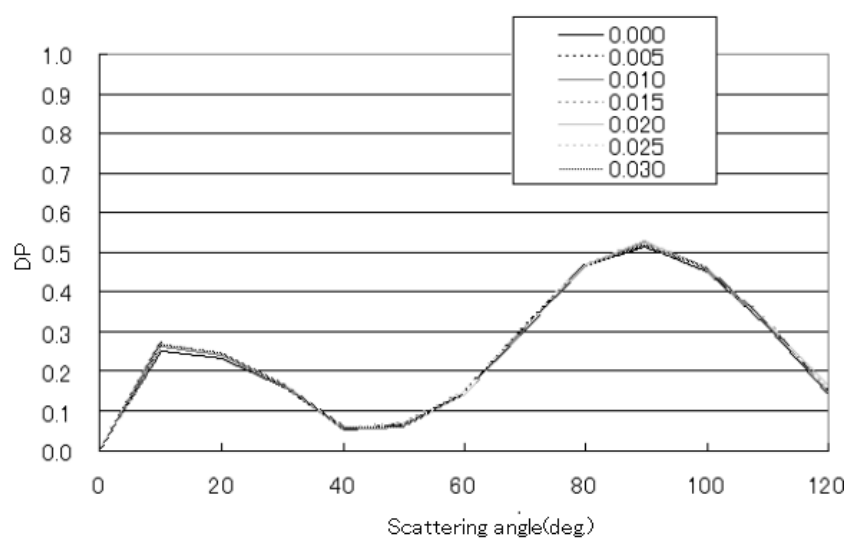

(g) DP as a function of imaginary part of refractive index

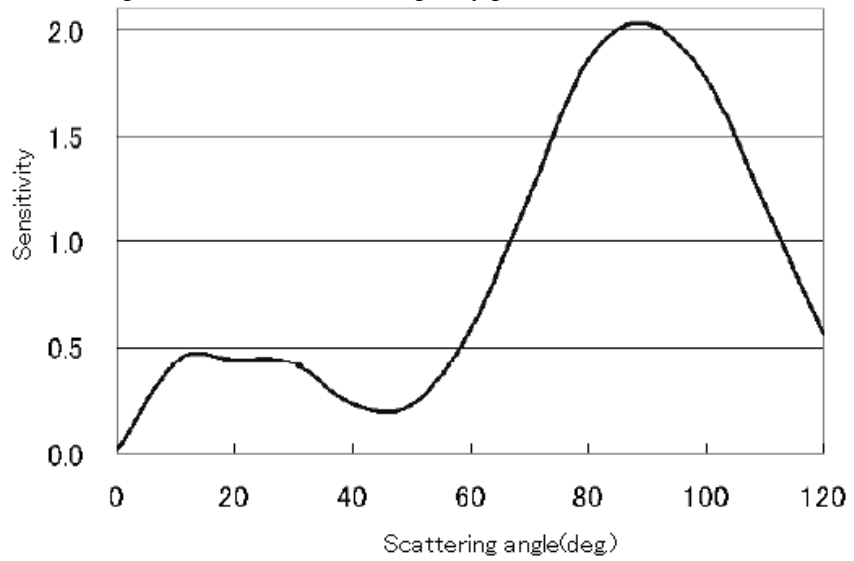

(h) DP sensitivity of imaginary part of refractive index

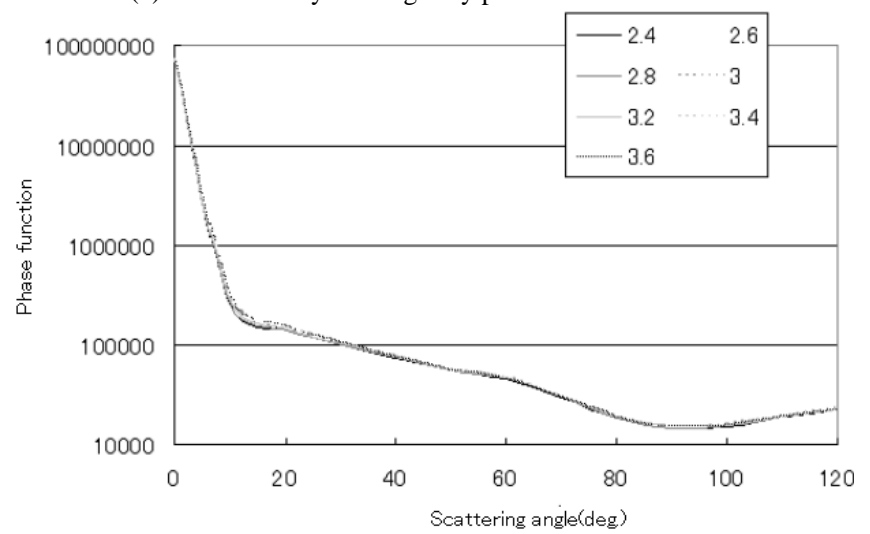

(i) Phase function of p polarized irradiance (Junge parameter)

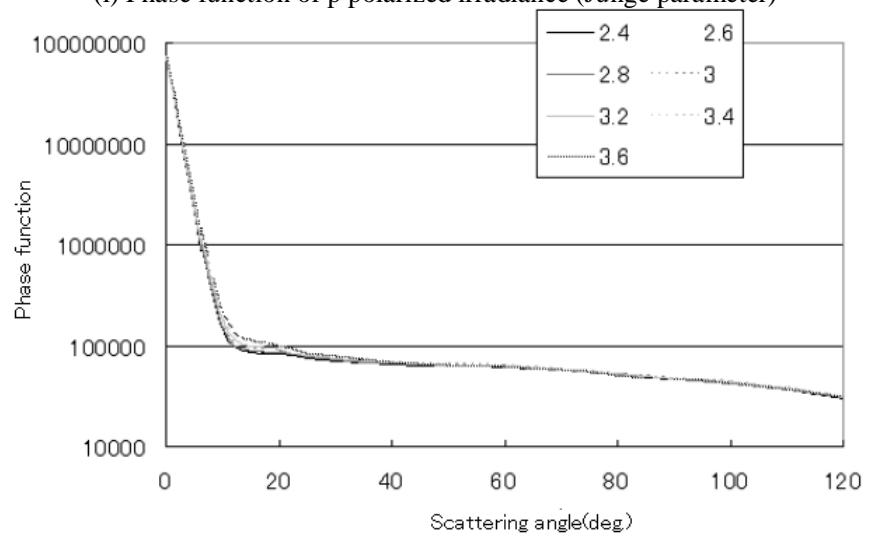

(j) Phase function of s polarized irradiance (Junge parameter) 


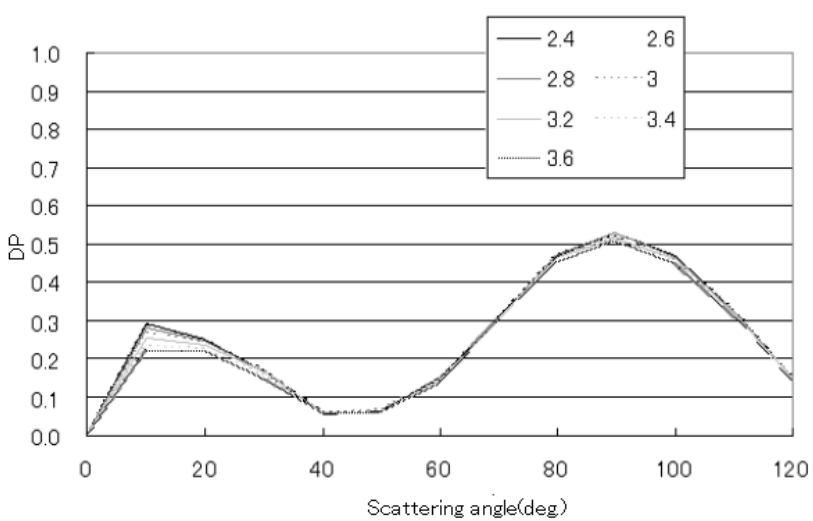

(k) DP as a function of Junge parameter

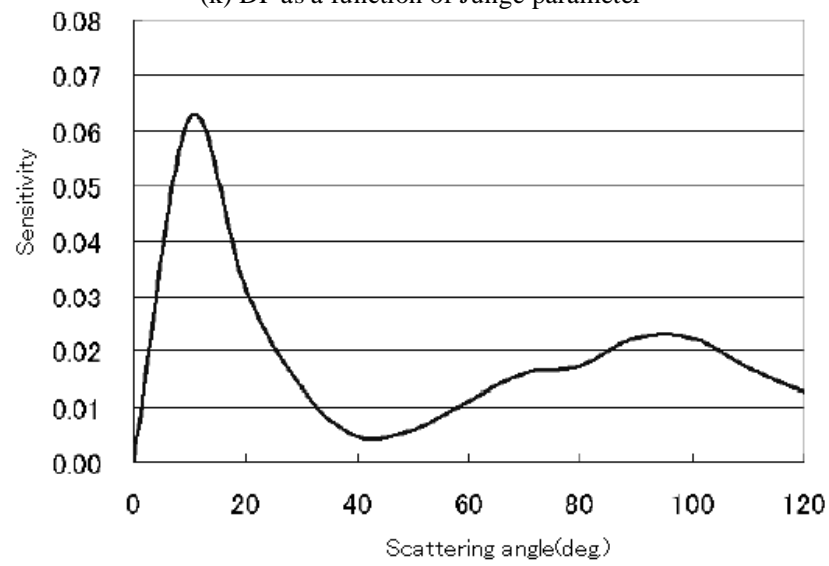

(l) DP sensitivity of Junge parameter

Fig. 4. Estimated phase function of $p$ and $s$ polarized irradiance, DP as functions of aerosol refractive index and Junge parameter, and DP sensitivity of refractive index and Junge parameter.

\section{F. Estimation of refractive index and size distribution}

Figure 5 shows the flowchart for refractive index and size distribution estimation. Using assumed Re, Im and Jp, p and s polarized phase function is estimated based on mie2new of software code included in MODTRAN. Then DP at 60, 70, 80, $90,100,110$, and 120 degrees of scattering angles is calculated. On the other hand, measured DP that is acquired at the corresponding scattering angles in the principal plane is compared to the calculated DP. To minimize the difference between both, Re, Im and Jp is changed by using golden section method. It is obvious that the golden section method of optimization cannot reach to a global optimum so that there is possibility to reach one of local minima.

\section{VALIDATION}

\section{A. Test Sites}

In order to validate the proposed method for refractive index and Junge parameter estimation with DP measurements, field campaigns were conducted at the test sites, Roach Lake in Nevada $\left(35: 38^{\prime} \mathrm{N}, 115: 22^{\prime} \mathrm{W}\right)$ during from $8: 00-8: 20$ on 3 December 2008 and Coyote Lake in California (35:04'N, $\left.116: 45^{\prime} \mathrm{W}\right)$ during 9:50-10:10 on 10 December 2008. Major characteristics of aerosol optical depth, molecule optical depth, surface reflectance ( $\mathrm{p}$ and $\mathrm{s}$ polarizations), and solar zenith angle for both test sites are shown in Table 2 .

\section{TABLE II. MAJOR Characteristics of The TeSt Sites}

\begin{tabular}{|c|c|c|c|c|c|}
\hline \multicolumn{6}{|c|}{ (a) Roach Lake playa } \\
\hline Wave & taero & $\tau \mathrm{mol}$ & $R e f p$ & Refs & $\operatorname{Sun} \theta$ \\
\hline $500 \mathrm{~nm}$ & 0.055 & 0.1630 & 0.364 & 0.354 & 63 \\
\hline $675 \mathrm{~nm}$ & 0.026 & 0.0534 & 0.494 & 0.442 & 63 \\
\hline $870 \mathrm{~nm}$ & 0.042 & 0.0127 & 0.580 & 0.549 & 63 \\
\hline \multicolumn{6}{|c|}{ (b) Coyote Lake playa } \\
\hline Wave & Taero & Tmol & Refp & Refs & $\operatorname{Sun} \theta$ \\
\hline $500 \mathrm{~nm}$ & 0.033 & 0.135 & 0.309 & 0.249 & 63 \\
\hline $675 \mathrm{~nm}$ & 0.011 & 0.0399 & 0.443 & 0.368 & 63 \\
\hline $870 \mathrm{~nm}$ & 0.017 & 0.0143 & 0.430 & 0.309 & 63 \\
\hline
\end{tabular}

Measured $\mathrm{p}$ and $\mathrm{s}$ polarized solar diffuse irradiance for the test site at Roach Lake and calculated DP are shown in Figure 6 (a), (b), and (c) while those for Coyote Lake are also shown in Figure 6 (d), (e), and (f), respectively.

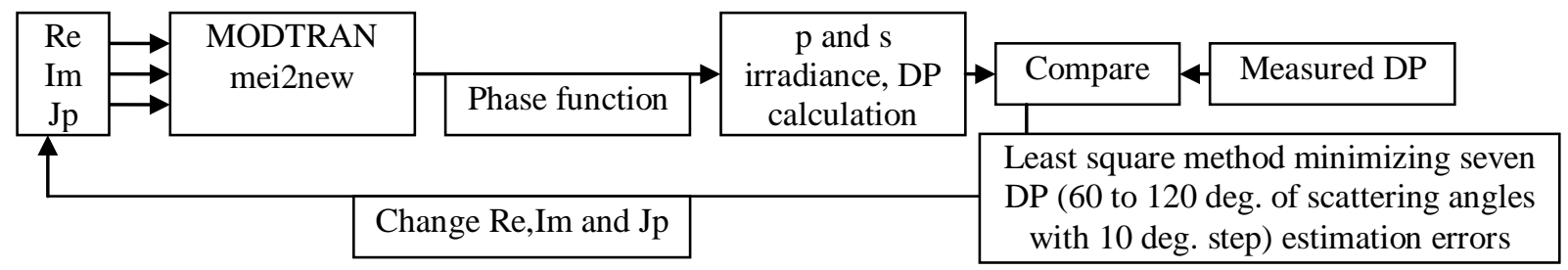

Fig. 5. Flowchart of the proposed method for refractive index and size distribution estimation process

DP for the scattering angle ranged from 60 to 120 at the wavelength of $500 \mathrm{~nm}$ shows specific feature while that of scattering angle ranged from 0 to 60 and that of $870 \mathrm{~nm}$ show unclear feature so that seven scattering angles of DP are used for aerosol refractive index and Junge parameter estimations.

\section{B. Measured and Estimated DP}

Figure 7 also shows the measured and the simulated DP. The simulated DP is calculated by means of MODTRAN with all the possible combination of refractive index and Junge parameters. The numbers of parameters of real and imaginary parts of refractive index as well as Junge parameter are seven so that the number of combinations is 343. DP that is shown in Figure 7 is the most resemble, or most appropriate curve in least square means. From these measured DP, DP corresponding to the scattering angles from 60 to 120 is selected with 10-degree step for estimation of refractive index and Junge parameter more precisely. 
There are seven DP data for each wavelength while unknown variables are three, real (Re) and imaginary (Im) parts of refractive index as well as Junge parameter (Jp) so that it is well posed problem. Least square method is applied, and then used for unknown variables estimation.

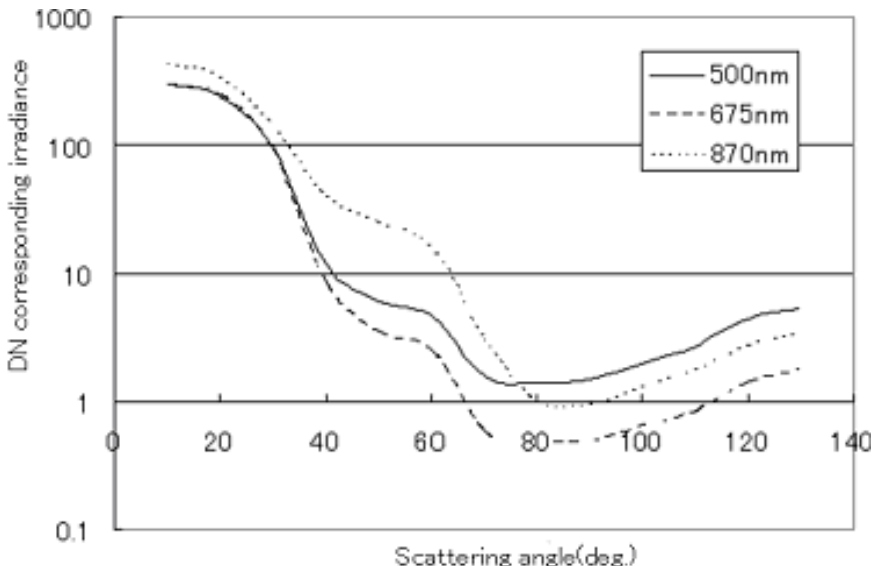

(a) Measured p polarized solar diffuse irradiance

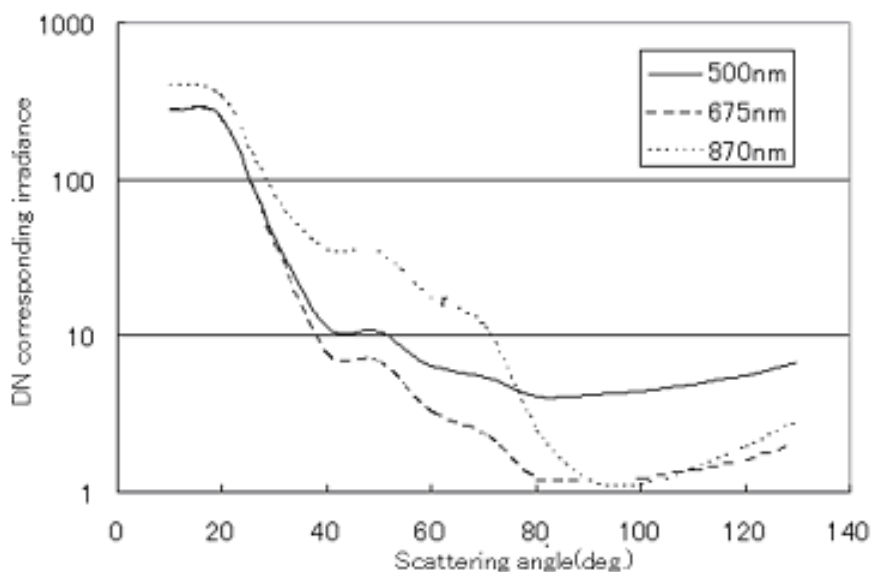

(b) Measured s polarized solar diffuse irradiance

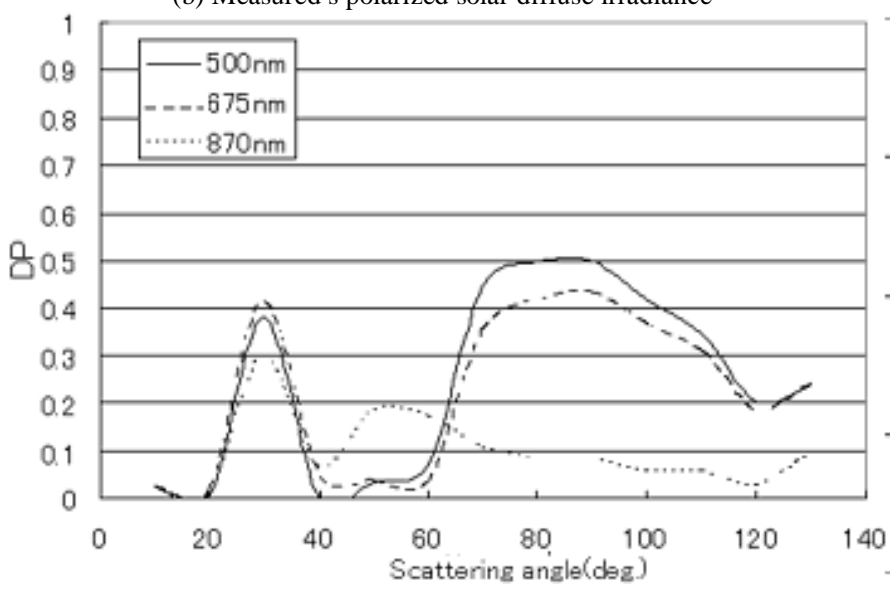

(c) Calculated DP

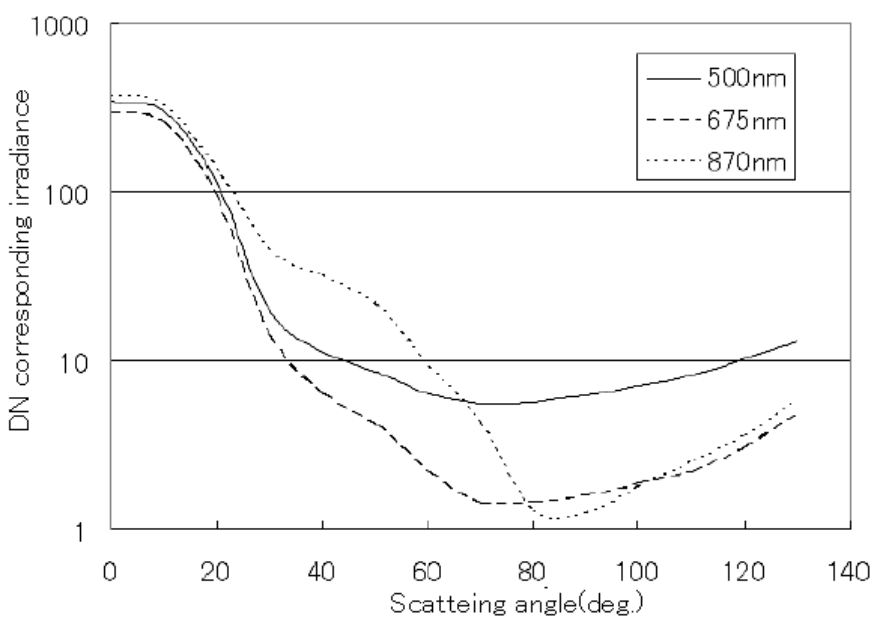

(d) Measured p polarized solar diffuse irradiance

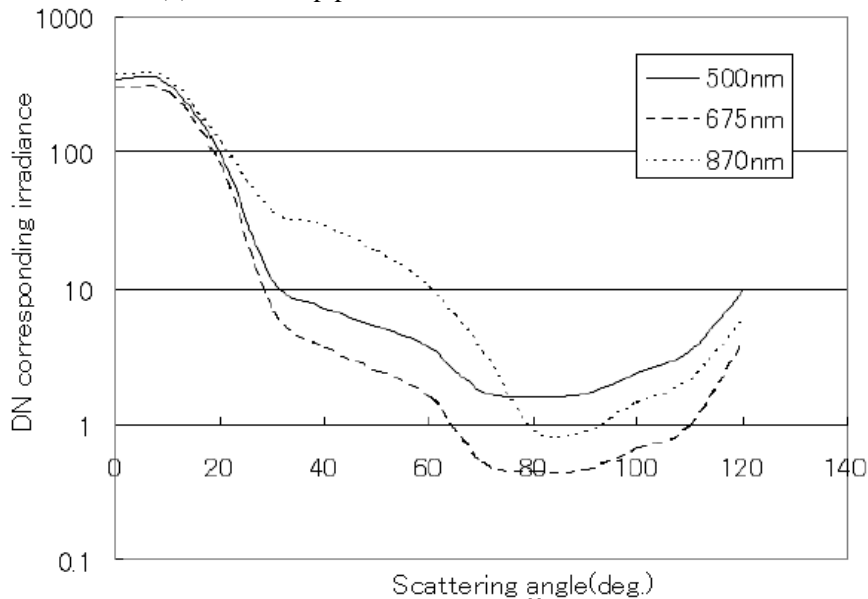

(e) Measured s polarized solar diffuse irradiance

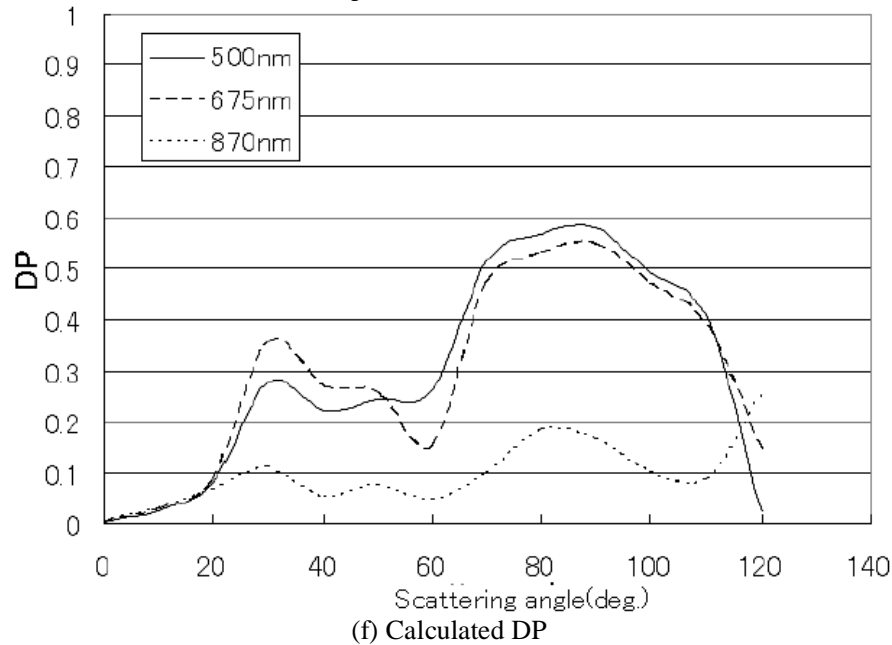

Fig. 6. Measured solar diffuse irradiance and calculated DP for the test site of Roach Lake (a), (b), and (c) and Coyote Lake (d), (e), and (f) on December 3 and 10 2008, respectively.

Table 3 shows the estimated Re, Im, and Jp for both test sites based on the proposed method with measured DP together with calculated $\mathrm{Re}, \mathrm{Im}$ and $\mathrm{Jp}$ derived from skyradiometer data, solar direct, diffuse and aureole based on skyradpack which allows estimations of refractive index and size distribution (volume spectrum). Estimation error of 
imaginary part of refractive index is greater than the other two parameters due to the fact that imaginary part is essentially small.

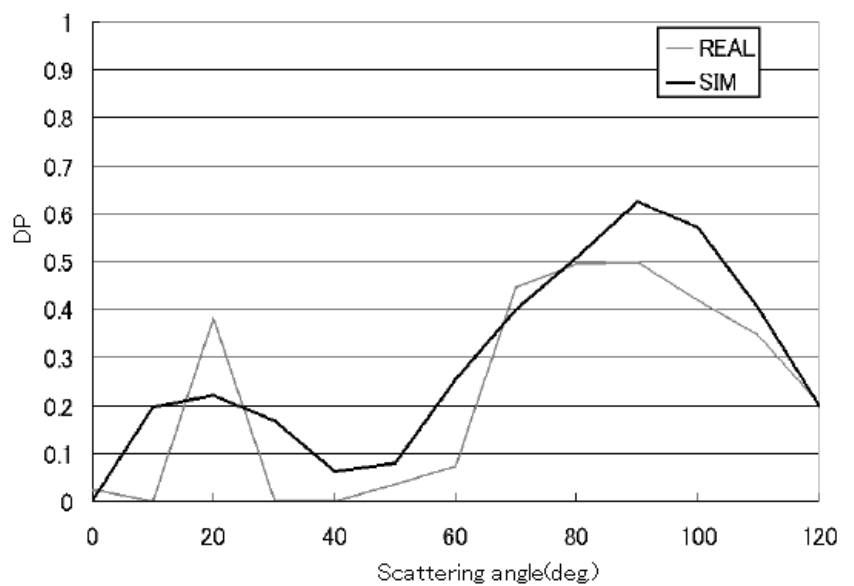

(c) DP measured at Roach Lake on 3 December 2008

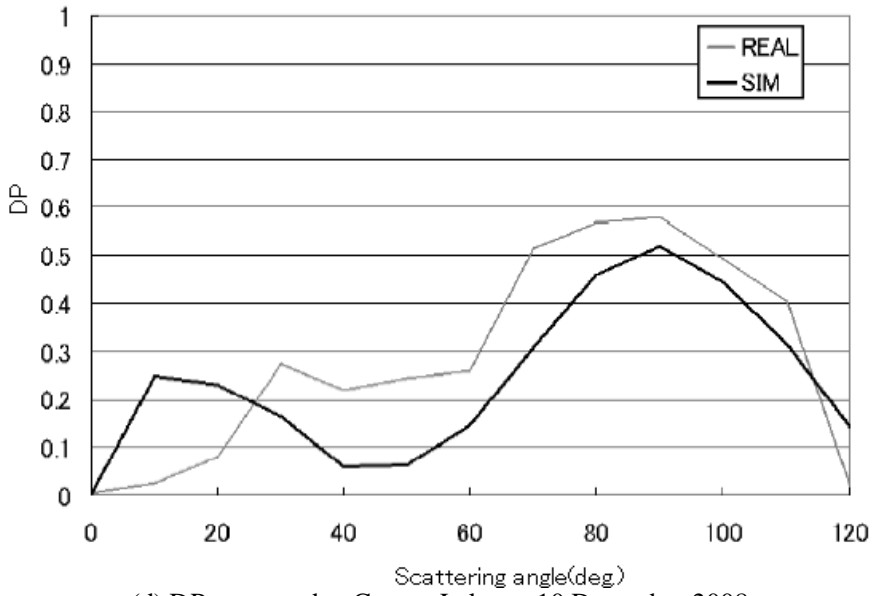

(d) DP measured at Coyote Lake on 10 December 2008

Fig. 7. Satellite images of the test sites, Roach Lake and Coyote Lake and measured (REAL) and simulated (SIM) DP.

TABLE III. ESTIMATION ERRORS FOR REFRACTIVE INDEX AND Junge PARAMETER AT 870 NM OF WAVELENGTH

\begin{tabular}{|c|c|c|c|c|c|c|c|}
\hline \multicolumn{3}{|c|}{ Roach Lake on 3 December 2008 } & \multicolumn{3}{c|}{ Coyote Lake on 10 December 2008 } \\
\hline $\begin{array}{c}\text { Param } \\
\text { eter }\end{array}$ & $\begin{array}{c}\text { Skyradio } \\
\text { meter }\end{array}$ & $\begin{array}{c}\text { Estim } \\
\text { ated } \\
\text { with } \\
\text { DP }\end{array}$ & $\begin{array}{c}\text { Error } \\
(\%)\end{array}$ & $\begin{array}{c}\text { Param } \\
\text { eter }\end{array}$ & $\begin{array}{c}\text { Skyradio } \\
\text { meter }\end{array}$ & $\begin{array}{c}\text { Estim } \\
\text { ated } \\
\text { with } \\
\text { DP }\end{array}$ & $\begin{array}{c}\text { Error } \\
(\%)\end{array}$ \\
\hline $\operatorname{Re}$ & 1.5459 & $\begin{array}{c}1.474 \\
0\end{array}$ & $\begin{array}{c}- \\
4.650\end{array}$ & $\operatorname{Re}$ & 1.5428 & $\begin{array}{c}1.582 \\
4\end{array}$ & 2.566 \\
\hline $\mathrm{Im}$ & 0.00031 & $\begin{array}{c}0.000 \\
292\end{array}$ & - & $\mathrm{Im}$ & 0.00645 & 0.006 & 3.846 \\
& & 3.365 & 3.653 & $\mathrm{Jp}$ & 5.2128 & 5.213 & 0.013 \\
\hline $\mathrm{Jp}$ & 3.3718 & 3 & & & & 2 & \\
\hline
\end{tabular}

\section{CONCLUSION}

It is found that the measured DP and calculated DP derived from MODTRAN show a good coincidence with below $10 \%$ of discrepancy. Also it is found that the estimated aerosol refractive index and size distribution (Junge parameter) based on the proposed method and those derived from the skyradiometer data of solar direct, diffuse, and aureole based on skyradpack with below $6 \%$ of discrepancy. It is concluded that the proposed method is validated.

The estimated refractive index and size distribution using the proposed DP based method shows a good coincidence with the estimated those by the conventional skyradiometer (POM01 which is manufactured by Prede Co.Ltd.), or aureole meter based method so that the proposed method does work well. The Junge parameter estimated by skyradiometer based method is derived from Angstrome exponent that is calculated with aerosol optical depth measured with skyradiometer while that by the proposed DP based method is derived from Angstrome exponent that is calculated with aerosol optical depth measured with polarized irradiance measuring instrument (MS720 which is manufactured by EKO Co.Ltd.). The difference between both is caused by the difference of gain/offset of the two instruments, POM-1 and MS720. On the other hand, the differences of estimated refractive index between skyradiometer based and the proposed DP based methods are mainly caused by the estimation methods, inversion of radiance to refractive index for skyradiometer based method while least square method minimizing the discrepancy between the actual and simulated DP at the seven different scattering angles based on MODTRAN.

It is obvious that skyradiometer and aureole meter is typically large and heavy in comparison to the polarized irradiance measuring instruments. It is possible to bring the polarized irradiance measuring instrument at anywhere easily. $\mathrm{p}$ and $\mathrm{s}$ polarized irradiance measurement at the seven different scattering angle takes around three minutes so that it has to be assumed that the atmosphere is stable for more than three minutes. $\mathrm{p}$ and $\mathrm{s}$ polarized irradiance is sensitive to the surface reflectance so that it is recommendable to use the proposed method for widely homogeneous ground cover targets.

\section{ACKNOWLEDGMENT}

The author would like to thank Mis. Yui Nishimura for her effort to conduct simulation

\section{REFERENCES}

[1] Aoki, K., T. Takamura, and T. Nakajima, Aerosol optical properties measured by SKYNET sky radiometer validation network. Proc. of the 2nd EarthCARE Workshop, 133-134, 2005.

[2] Clapp M.L., and R.E.Miller, Complex Refractive Indices of Crystalline Hydrazine from Aerosol Extinction Spectra, Icarus, 23, 2, 396-403(8), 1996.

[3] Eiden R., Determination of the complex index of refraction of spherical aerosol particles, Appl. Opt. 10, 749-757, 1971.

[4] Holben, B. N., et al., AERONET- A federated instrument network and data achieve for aerosol characterization, Remote Sens., 12, 1147-1163, 1991.

[5] Holben, B.N., and Coauthors, AERONET-A federated instrument network and data archive for aerosol characterization. Remote Sens. Environ., 66, 1-16. 1998.

[6] Hoppel, W. A., J. W. Fitzgerald, G. M. Frick, R. E. Larson, and E. J. Mack, Aerosol size distributions and optical properties found in the marine boundary layer over the Atlantic Ocean, J. Geophys. Res., 95, 3659-3686, 1990.

[7] Redemann, J., R. P. Turco, K. N. Liou, P. B. Russell, R. W. Bergstrom, B. Schmid, J. M. Livingston, P. V. Hobbs, W. S. Hartley, S. Ismail, R. A. Ferrare, E. V. Browell, Retrieving the vertical structure of the effective aerosol complex index of refraction from a combination of aerosol in 
situ and remote sensing measurements during TARFOX, J. Geophys. Res., 105, D8, 9949-9970, 2000.

[8] Shaw, G.E., Error analysis of multi-wavelength sunphotometry. Pure Appl. Geophys., 114, 1, 1976.

[9] Thomas G.E., S. F. Bass, R. G. Grainger, and A. Lambert, Retrieval of aerosol refractive index from extinction spectra with a damped harmonic-oscillator band model, Appl. Opt. 44, 1332-1341, 2005.Booth, N. and Smith, A. S., [Infrared Detectors], Goodwin House Publishers, New York \& Boston, 241-248 (1997).

[10] Davis, A., R., Bush, C., Harvey, J. C. and Foley, M. F., "Fresnel lenses in rear projection displays," SID Int. Symp. Digest Tech. Papers 32(1), 934-937 (2001).

[11] Van Derlofske, J. F., "Computer modeling of LED light pipe systems for uniform display illumination," Proc. SPIE 4445, 119-129 (2001).

[12] C. Jones (private communication).

[13] J. Rivers, http://awebsiteref.com

\section{AUTHORS PROFILE}

Kohei Arai, He received BS, MS and PhD degrees in 1972, 1974 and 1982, respectively. He was with The Institute for Industrial Science, and Technology of the University of Tokyo from 1974 to 1978 also was with National Space Development Agency of Japan (current JAXA) from 1979 to 1990. During from 1985 to 1987, he was with Canada Centre for Remote Sensing as a Post Doctoral Fellow of National Science and Engineering Research Council of Canada. He was appointed professor at Department of Information Science, Saga University in 1990 . He was appointed councilor for the Aeronautics and Space related to the Technology Committee of the Ministry of Science and Technology during from 1998 to 2000. He was also appointed councilor of Saga University from 2002 and 2003 followed by an executive councilor of the Remote Sensing Society of Japan for 2003 to 2005. $\mathrm{He}$ is an adjunct professor of University of Arizona, USA since 1998. He also was appointed vice chairman of the Commission "A" of ICSU/COSPAR in 2008. He wrote 30 books and published 332 journal papers 